The Development of the Basic Obstetric Ultrasound Learning Media for Undergraduate Medical Students

\title{
HERLAMBANG,${ }^{1}$ AMELIA DWI FITRI, ${ }^{2}$ NYIMAS NATASHA AYU SHAFIRA, ${ }^{3}$ ELFIANI, ${ }^{4}$ ANGGELIA PUSPASARI, ${ }^{5}$ AND SUSAN TARAWIFA ${ }^{6}$
}

\begin{abstract}
Current medical education curriculum refers to the Indonesian Medical Doctor's Standard of Competence 2012. Competencies are detailed in seven general areas of competence to be achieved by medical students. This study focused on the development of learning media in the form of guide book and video related to the basic obstetric ultrasound examination and its influence in improving student's knowledge of basic obstetric examination skills. A quantitative method used to see the effectiveness of the learning media that we developed. Twenty-one under graduate medical students who undertook clinical rotation in the Department of Obstetrics and Gynecology participated in this study through completing the pre-post student's questionnaires to assess the students' knowledge before and after the delivery of learning media. The collected data were analyzed with a computer program; Means and Standard Deviation were calculated as descriptive parameters. Parametric tests were used to test the hypotheses. The pre-post results were compared using the Wilcoxon statistical test. The results showed a significant difference in the score of pretest and posttest. There was an increase in the average score of pretest and posttest for students after obtaining the teaching media and clinical supervision. The value of each individual was also increased. The analysis with the Wilcoxon statistical test showed significant differences which mean that there were improvements on student's knowledge of basic obstetric examination skills after the delivery of guide book and video. The use of teaching media in the form of basic obstetric ultrasound module and video contributed to positive results to improve the student's knowledge.
\end{abstract}

\section{Keywords}

Learning media, medical education curriculum, medical students

1 The Department of Obstetric and Gynecology, Faculty of Medicine and Health Sciences, Universitas Jambi, Indonesia; herlambang07@yahoo.co.id

$2 *$ Corresponding author, the Department of Medical Education, Faculty of Medicine and Health Sciences, Universitas Jambi, Indonesia; amelia_dwi@unja.ac.id

3 The Department of Medical Education, Faculty of Medicine and Health Sciences, Universitas Jambi.

4 Faculty of Medicine and Health Sciences, Universitas Jambi, Indonesia.

5 The Department of Biochemistry, Faculty of Medicine and Health Sciences, Universitas Jambi, Indonesia.

6 Faculty of Medicine and Health Sciences, Universitas Jambi, Indonesia. 


\section{IRJE | Indonesian Research Journal in Education | |Vol. 4| No. 1|June | Year 2020|}

\section{Introduction}

Ultrasound is one of the modern tools to guide a doctor to facilitate patient's diagnostic procedure. Obstetrics and gynecology is a branch of medical sciences that use ultrasound in daily practices. The use of ultrasound is widely for basic examination of pregnant women, and also for the diagnosis of cases in the field of obstetrics and gynecology. There is a general consensus that basic obstetric Ultrasound is an important skill to teach in medical schools. The integration of ultrasound is highly variable in the worldwide. In the U. S. medical school curricula, there is a national standard to guide the integration of ultrasound education (Bahner, Goldman, Way, Royall, \& Liu, 2014). In Indonesia, the current medical education curriculum refers to the Indonesian Medical Doctor's Standard of Competence 2012. Competencies are detailed in seven general areas of competence to be achieved by medical students. Clinical skills mastery is an important element determining the quality of professionalism of medical higher education graduates. The Indonesian medical doctor's standard of competence places the mastery of basic obstetric ultrasound examination in the $4^{\text {th }}$ level of competence; it means that graduates should able to independently perform this skill in primary health care (Indonesia, 2012). However, the integration of ultrasound education programs into the undergraduate medical education model remains a challenge, efforts to integrate ultrasound technologies into undergraduate medical education are limited, and a national consensus has not been reached regarding their role in the medical education system. In addition, teaching media that can be used as a reference containing every detailed step of basic obstetric ultrasound examination are still very limited.

To overcome this problem, it is necessary to develop instructional media that can be used as a medium to integrate basic obstetric ultrasound examination education into learning curricula. In this Study, we developed two instructional media in the form of guide book and a video of basic obstetric ultrasound examination. Then, the effectiveness of the instructional media developed was assessed by assessing student's knowledge before and after receiving the learning media. This was a preliminary study; the result of this study would be used as part of learning media in integrating process of ultrasound education into learning curricula. To achieve the goal of the study, one general research question guided this study: What is medical students' knowledge before and after receiving the learning media?

\section{Literature Review}

There are three categories of learning methods, namely (1) expository, (2) exploratory, and (3) simulation. The expository method is unidirectional delivery or representation of information to the learners. Exploratory method prompts the learners to explore and discover by way of interaction. It allows and encourages a two-way exchange of information such as discussion, question and answer and brainstorm. Simulation is a teaching and learning method that allows practice of learned skills in a safe situation that 


\section{IRJE | Indonesian Research Journal in Education | |Vol. 4| No. 1|June | Year 2020|}

closely resembles real life, this method allows the careful and gradual transfer of learned skills into actual practices. Role play and standardized patients are examples of simulation in medical education(Amin \& Eng, 2003).

The Association of American Medical Colleges 's Institute for improving medical education (AAMC-IME) highlights the importance of multimedia learning and suggests that medical educators should utilize multimedia learning principles when designing learning media for medical students. A critical point is that faculty development programs should encourage lecturers to understand how people learn best from words and pictures, based on the theoretical underpinnings of multimedia learning theory and accordingly to understand how to design effective multimedia instructional messages (Issa et al., 2011). Most clinical faculty staff involving in medical education lack formal or structured training in the science of teaching prior to beginning their duties as educators. Faculty development programs should provide learning media that enhance the learning process for students. The emphasis on understanding the cognitive process of learning, rather than simply following certain design rules, is the key. This process is especially relevant in medical education as a significant proportion of medical learning occurs through a variety of multimedia formats, such as didactic lectures, small-group sessions, traditional module and web-based modules, among other applications (DiGiacinto, 2007; Issa et al., 2011; Levinson, 2010).

Video use in health professions education has risen exponentially in the past decade. For example, Stanford University School of Medicine has collaborated with the Khan Academy to develop and teach the core curriculum using short video clips in a flipped classroom model. YouTube videos have been widely used in health professions education. Medical schools that have been through curricular reform are increasingly adopting the clinical competency outcome framework. Well-designed videos offer medical students the flexibility to review material at their own pace to address their individual learning needs under this framework. Many students already skip lectures and solely access educational materials online in digital format. Ideally, educational theories and best practices should guide the use of videos. Research on the effective use of technology in education shows that instructors need to be not only subject matter experts, but also have an empirical understanding of the technology to be used to deliver the content, as well as the teaching and learning pedagogy underpinning the use of a particular instructional format (Billings-Gagliardi \& Mazor, 2007; Cooke, Irby, Sullivan, \& Ludmerer, 2006; Prober \& Khan, 2013; Roblyer \& Doering, 2012).

Ultrasound technology is generally considered to be reliable and widely used by physician today. Ultrasound training for undergraduate medical students has been increasingly incorporated into curriculum. Ultrasound is imaging modality based on the use of high frequency sound. Transformation of sound energy is to electric and further processes to form image. Ultrasound wave originates from transducer, propagates through different tissue density and then returns to the transducer as reflected echo. Reflected echo converted back into electrical impulses by transducer and processes as images with different echo. Ultrasound in obstetric is a main modality that has been widely used because its safety and noninvasive. Ultrasound screening in the first trimester of pregnancy performs to define 


\section{IRJE | Indonesian Research Journal in Education | |Vol. 4| No. 1|June | Year 2020|}

intra-exstrauterine pregnancy, measure gestational age (measure diameter of gestational sac, yolk sac, and crown-rump length), measure cardiac activity and detect any early fetal abnormality. Ultrasound screening in the second and third trimester of pregnancy aims to define single or multiple pregnancy, measure amnion fluid volume, define placental structure and location, biometry measurement for gestational age and fetal growth assessment, and screening for fetal anomaly (Baltarowich et al., 2014; Limchareon, Asawaworarit, Klinwichit, \& Dinchuthai, 2016; Pinto, Wankelmuth, \& D'Addario, 2004).

There has been growing interest in undergraduate ultrasound education among educators and students in recent years. The number of citations reported in a PubMed search for Ultrasound has increased more than 2, 5 times since 2006 from 351 to over 900 in 2014. Historically, students have had little ultrasound education and almost no hands-on scanning experiences while they are in medical schools. However, this is changing and more medical schools are introducing ultrasound into their curricula. An argument can be made that ultrasound should be seriously considered for inclusion as a core competency for all medical students (Dinh et al., 2016; Hoppmann et al., 2015).

Ultrasound curriculum is also presented as thoughts on future directions of undergraduate ultrasound education. Ultrasound has proven to be a valuable active learning tool that can serve as a platform for integrating medical student curriculum across disciplines and clinical settings. It is also well-suited for a competency-based model of medical education. Students can learn ultrasound well and have embraced it as an important component of their education and future practice of medicine. An international consensus conference on ultrasound education is recommended to help define the essential elements of ultrasound education globally to ensure ultrasound is taught and ultimately practiced to its full potential. Ultrasound has the potential to fundamentally change how we teach and practice medicine to the benefit of learners and patients across the globe (Dinh et al., 2016; Hoppmann et al., 2015). Over the past 10 years, medical schools around the globe have begun to implement ultrasound into their curricula, and ultrasound has proved to enhance student education in physical examination, in basic sciences, as well as on clinical rotations. Medical schools that provide point-of-care ultrasound training have shown that students find it useful in various aspects of medical education and expressed interest in obtaining further education in ultrasound, integration of ultrasound into the medical school curriculum is feasible and beneficial to medical students (Birrane, Misran, Creaney, Shorten, \& Nix, 2018; Dinh et al., 2016).

\section{Methodology}

We developed two learning media in this research, which was in the form of guidebook and video about the basic principles of obstetric ultrasound examination. Guidebook was prepared in accordance with the standards of examination of pregnant women made by the association of obstetrists and gynecologists in Indonesia as well as international standard. This manual contains step-by-step instructions on how to perform basic obstetric ultrasound examination in the first, second and third trimester pregnant 


\section{IRJE | Indonesian Research Journal in Education | |Vol. 4| No. 1|June | Year 2020|}

women. It also contains the essentials things that need to be identified as a preliminary screening of a normal pregnancy.

Video was developed on the same principle as in the guidebook, using twelve tips and implementation strategies for using videos in health professions education. Video performed by obstetricians and gynecologists with fetomaternal consultant background, who were also active in undergraduate medical education, familiar with the topic and had lectured on it for several years, involving three mothers with normal pregnancies and single fetuses, each representing the first, second and third trimester of pregnancy. Cinematic aspects of the video were done by the experts.

We also developed a questionnaire about student knowledge in basic obstetric ultrasound, consisting of 20 multiple choice questions. The validity of the questionnaire was reviewed in two stages. First, the questionnaire was evaluated by a panel of health profession education experts including faculty members. After being declared as valid by the panel of experts, the questionnaire was assessed for validity using the Spearman rank correlation coefficient rho, which resulted in the probability value $\mathrm{p}>0.05$. The reliability of the questionnaire was tested using Cronbach's alpha which resulted in the reliability coefficients in the range $0.892-0.898$ indicating the high reliability of the questionnaire and its items. The questionnaire was written in the Indonesian language. To assess the efficiency of the learning media that we developed, we conducted an experimental study, involving 21 medical students in year five who experienced a clinical rotation in the Department of Obstetric and Gynecology, Raden Mattaher General Hospital. We used one group pre and posttest design to assess the difference of student knowledge about basic obstetric ultrasound before and after we gave two learning media that we developed and one group posttest design to assess students' skills achievement.

We handed pretest questionnaire consisting of 20 questions related basic obstetric ultrasound principles, students were expected to learn by using both media independently and tried to find as many opportunities as possible to observe clinical teachers in wards and ambulatory care conducted ultrasound examination. At the end of their rotation, the students completed the post questionnaire using the same questions they encountered during pretest. A descriptive analysis was performed, and data were presented as mean and standard deviation, minimum and maximum, and number and percentage. The MannWilcoxon test was used for comparison of continuous or ordinal variables, Statistical significance was determined at $\mathrm{P}<.05$.

\section{Ethical considerations}

In this study, all personalities of students were concealed. Additionally, all personalities regarding data bases were masked. All students were also knowledgeable that all their information would be kept privately by investigators.

\section{Findings}

This study focused on the development of learning media in the form of guide book 


\section{IRJE | Indonesian Research Journal in Education | |Vol. 4| No. 1|June | Year 2020|}

and video related to the basic obstetric ultrasound examination and its influence in improving student's knowledge of basic obstetric examination skills. The results showed a significant difference in the score of pretest and posttest. There was an increase in the average score of pretest and posttest students after obtaining the teaching media and clinical supervision. In the pretest, we found the mean value of 24.14; minimum value of 15; and a maximum value of 55 . In the posttest, we found the mean value of 75.45 , a minimum value of 55 , and a maximum value of 90 , as showed in the table below. The value of each individual was also increased.

Table 1. Result of the pre-post questionnaire

\begin{tabular}{lll}
\hline & \multicolumn{1}{c}{ Descriptive } \\
\hline \multirow{3}{*}{ Pretest } & Statistic value \\
& Mean & 24.14 \\
& $95 \%$ confidence interval for mean & \\
& Lower bound & 21.22 \\
& Upper bound & 32.10 \\
Median & 35.00 \\
Variance & 121.150 \\
Std. Deviation & 11.200 \\
Minimum & 15 \\
Paximum & 55 \\
Range & 40 \\
Mean & 75.45 \\
& 95\% confidence interval for mean & \\
Lower bound & 71.82 \\
& Upper bound & 84.00 \\
Median & 75.00 \\
& Variance & 151.222 \\
Std. Deviation & 12.560 \\
Minimum & 55 \\
Maximum & 90 \\
Range & 40 \\
\hline
\end{tabular}

The result of the test of normality for the pre and post test data showed abnormal data distribution, based on that result that we used Wilcoxon test as selected statistical analysis test, as showed in the table below.

Table 2. Test of normality

\begin{tabular}{lllllll}
\hline \multicolumn{7}{c}{ Test of normality } \\
\hline & \multicolumn{7}{c}{ Kolmogorov-Smirnov } & Shapiro-Wilk & \\
& Statistic & df & Sig & Statistic & df & Sig \\
Pretest & .192 & 21 & .035 & .904 & 21 & .046 \\
Posttest & .272 & 21 & .000 & .843 & 21 & .005 \\
\hline
\end{tabular}




\section{IRJE | Indonesian Research Journal in Education | |Vol. 4| No. 1|June | Year 2020|}

The result of Wilcoxon statistical analysis test showed significant differences (Asymp Sig 2 -tailed 0.000 ) between the value of pretest and posttest, which means there were improving on student's knowledge of basic obstetric examination skills before and after the giving of handbook and video.

The answers to open questions were processed; all the students stated that the guidebook could provide them with sufficiently clear information about basic obstetric ultrasound examination, helping them learn the steps to be taken to identify important matters in pregnant women. In the case of a given video, the students stated that the video given was very interesting and informative. In terms of content, the video was presented with a clear sequence of steps, ranging from instrument preparation, patient preparation, placing the transducer to the patient's stomach and directing the target to be searched. The cinematic aspects such as sound and picture quality is also very good, covering multiple angles of image for each stage of examination helps students to understand how to use ultrasound for basic obstetric examination. But some students claim that to be able to have the expected $4^{\text {th }}$ level of competence in this skill, according to the Indonesian Medical Doctor's Standard of Competence 2012, it will be very helpful if they had an opportunity for being guided directly by the clinical teacher frequently, for certain schedule and experience to the real patients.

\section{Discussion}

There is a well-recognized paucity of medical education research on the effects of utilizing cognitive load theory and multimedia design principles on the learning of medical professionals. This study builds on the work that cognitive psychologists such as have already carried out in the science of instructional design. We found that learning media in the form of guidebook and video development in this study was good enough to encourage learning process and improve student cognitive issues. Twelve tips in arranging multimedia have been applied through instructional video made by demonstrating standard procedures in sequence. There is an orientation to video content, learning achievement to be achieved, spacing or time lag between each segment of the video was made clear so that at the time of watching the video students can learn each segment well. Video was also made by paying attention to the efficiency and effectiveness of the time of the download, the duration of the video was 25 minutes. This time is considered enough to make the students watch and remain interested in seeing the video content from beginning to end. videos were made professionally from both the concept and content aspects of learning and in terms of video cinematic quality (Herlambang et al., 2018; Issa et al., 2011; Mayer, 2010).

Videos also stimulate curiosity and engage students' attention by situating them in realistic clinical scenarios, and promoting authentic learning. Students could play video frequently fast-forward to or replayed sections of the video as needed. They could choose pause section for a moment if they wanted to focus on the certain aspects and this learning process could also be done during their spare time along their activities in clinical rotation. It

|E-ISSN: 2580-5711 | https://online-journal.unja.ac.id/index.php/irje/index | 


\section{IRJE | Indonesian Research Journal in Education | |Vol. 4| No. 1|June | Year 2020|}

could overcome the limitations of human resources (clinical teacher) and time related to the difficulty of facilitating repetitive ultrasound clinical supervision activities. But this unscheduled session is also the limitation of this study. Our study was carried out during an actual core curriculum session with uncontrolled setting and student distractions. Learning by doing requires an appropriate and controlled learning environment. The selection of an appropriate learning situation is the decisive factor for a sustainable learning experience (Dahmen et al., 2016; Herlambang et al., 2020; Herlambang et al., 2019; Mayer, 2010).

The findings are generally consistent with those obtained by Mayer (2010) with undergraduate students as participants, and showed that multimedia design principles can be successfully applied in medical education. However, the results of this study did not show that multimedia design principles improved students' ability to apply the newly acquired knowledge and psychomotor competence to clinical skills. Guidebook and video still cannot replace other roles which are required in training students' clinical skills. The role of clinical supervision in scheduled guidance sessions with the real patient is really needed, as well as the opportunity for the students to hands on directly to patients, the need for constructive feedback repeatedly so that students are able to self-reflected, learn continuously and improve performance gradually until finally able to mastery the clinical skills. What needs to be considered is the need for adequate resources and time to facilitate this activity. Clinical teachers should spend considerable time along their medical service and research activities, because practicing skills on students cannot be done only once, must be frequently, repetitive and continuously with constructive feedback (Mayer, 2003, 2010).

\section{Conclusion and Implications}

The findings showed a significant difference in the score of pretest and posttest. There was an increase in the average score of pretest and posttest for students after obtaining the teaching media and clinical supervision. The value of each individual was also increased. The analysis with the Wilcoxon statistical test showed significant differences which mean that there were improvements on student's knowledge of basic obstetric examination skills after the delivery of guide book and video. The use of teaching media in the form of basic obstetric ultrasound module and video contributed to positive results to improve the student's knowledge. Therefore, the role of faculty is essential to encourage the resources involved to integrate these skills guidance activities in the preclinical phase and clinical phase curriculum, develop strategies that can make the clinical supervisions are willing to spend their time and energy on the sidelines of their role in health services and research, the ultimate goal is none other so that students can achieve competence according to the expected standard demands. Teaching basic obstetric ultrasound skills for undergraduate medical students should be incorporated in to curriculums.

\section{Disclosure statement}

No conflict of interest was reported by the authors. 


\section{IRJE | Indonesian Research Journal in Education | |Vol. 4| No. 1|June | Year 2020|}

\section{Acknowledgments}

We would like to thank all participants who participated in this study. Also we would like to thank IRJE and reviewers for accepting our article. The authors thank to dr. Asro Hayani Harahap and dr. Hernina Oktaviani for their great help and support in this study.

\section{References}

Amin, Z., \& Eng, K. (2003). Overview of teaching and learning methods. Basics in Medical Education. World ScientificPublishing Co, Singapura, pág, 99-103.

Bahner, D. P., Goldman, E., Way, D., Royall, N. A., \& Liu, Y. T. (2014). The state of ultrasound education in US medical schools: Results of a national survey. Academic Medicine, 89(12), 1681-1686.

Baltarowich, O. H., Di Salvo, D. N., Scoutt, L. M., Brown, D. L., Cox, C. W., DiPietro, M. A., \& Nazarian, L. N. (2014). National ultrasound curriculum for medical students. Ultrasound quarterly, 30(1), 13-19.

Billings-Gagliardi, S., \& Mazor, K. M. (2007). Student decisions about lecture attendance: do electronic course materials matter? Academic Medicine, 82(10), S73-S76.

Birrane, J., Misran, H., Creaney, M., Shorten, G., \& Nix, C. M. (2018). A scoping review of ultrasound teaching in undergraduate medical education. Medical Science Educator, 28(1), 45-56.

Cooke, M., Irby, D. M., Sullivan, W., \& Ludmerer, K. M. (2006). American medical education 100 years after the Flexner report. New England journal of medicine, 355(13), 1339-1344.

Dahmen, U., Schulze, C., Schindler, C., Wick, K., Schwartze, D., Veit, A., \& Smolenski, U. (2016). Recommendations to enhance constructivist-based learning in Interprofessional Education using video-based self-assessment. GMS journal for medical education, 33(2).

DiGiacinto, D. (2007). Using multimedia effectively in the teaching-learning process. Journal of Allied Health, 36(3), 176.

Dinh, V. A., Fu, J. Y., Lu, S., Chiem, A., Fox, J. C., \& Blaivas, M. (2016). Integration of ultrasound in medical education at United States medical schools: a national survey of directors' experiences. Journal of Ultrasound in Medicine, 35(2), 413-419.

Herlambang, Fitri, A. D., \& Puspasari, A. (2018). Skrining dan tatalaksana anemia pada ibu hamil di wilayah kerja puskesmas muaro kumpeh dan klinik Mer-C Jambi. Jurnal MEDIC (Medical Dedication), 1(1), 1-7.

Herlambang, Fitri, A. D., \& Kusdiyah, E. (2020). Peningkatan pengetahuan tentang ca cerviks dan pemeriksaan iva test di nyogan muaro Jambi. Jurnal MEDIC (Medical Dedication), 3(1), 45-47.

Herlambang, Kusdiyah, E., \& Iskandar, M.M. (2019). Peningkatan pengetahuan wanita tentang kanker serviks dan pemeriksaan pap smear sebagai skrining awal. Jurnal MEDIC (Medical Dedication), 2(1), 25-28. 


\section{IRJE | Indonesian Research Journal in Education | | Vol. 4 | No. 1|June | Year 2020|}

Hoppmann, R. A., Rao, V. V., Bell, F., Poston, M. B., Howe, D. B., Riffle, S., \& Wilson, L. B. (2015). The evolution of an integrated ultrasound curriculum (iUSC) for medical students: 9-year experience. Critical ultrasound journal, 7(1), 18.

Indonesia, S. K. D. (2012). Peraturan KKI No. 11/2012. KKI. Jakarta.

Issa, N., Schuller, M., Santacaterina, S., Shapiro, M., Wang, E., Mayer, R. E., \& DaRosa, D. A. (2011). Applying multimedia design principles enhances learning in medical education. Medical education, 45(8), 818-826.

Levinson, A. J. (2010). Where is evidence-based instructional design in medical education curriculum development? Medical education, 6(44), 536-537.

Limchareon, S., Asawaworarit, N., Klinwichit, W., \& Dinchuthai, P. (2016). Development of the ultrasonography learning model for undergraduate medical students: A case study of the Faculty of Medicine, Burapha University. Journal of the Chinese Medical Association, 79(8), 445-449.

Mayer, R. E. (2003). Learning and instruction: Prentice Hall.

Mayer, R. E. (2010). Applying the science of learning to medical education. Medical education, 44(6), 543-549.

Pinto, V., Wankelmuth, M., \& D'Addario, V. (2004). Donald school textbook of ultrasound in obstetrics and gynecology. Asim Kurjak, Frank. A Chervenak, First Ed, Jaypee Brothers, New Delhi, India, 365.

Prober, C. G., \& Khan, S. (2013). Medical education reimagined: a call to action. Academic Medicine, 88(10), 1407-1410.

Roblyer, M. D., \& Doering, A. H. (2012). Integrating educational technology into teaching.

\section{Biographical notes}

Dr. HERLAMBANG works at the Department of Obstetric and Gynecology, Faculty of Medicine and Health Sciences, Universitas Jambi, Indonesia; email: herlambang07@yahoo.co.id

dr. AMELIA DWI FITRI works at the Department of Medical Education, Faculty of Medicine and Health Sciences, Universitas Jambi, Indonesia; email: ameliadwi@unja.ac.id

dr. NYIMAS NATASHA AYU SHAFIRA works at the Department of Medical Education, Faculty of Medicine and Health Sciences, Universitas Jambi, Indonesia.

dr. ELFIANI works at Faculty of Medicine and Health Sciences, Universitas Jambi, Indonesia

dr. ANGGELIA PUSPASARI works at The Department of Biochemistry, Faculty of Medicine and Health Sciences, Universitas Jambi, Indonesia.

dr. SUSAN TARAWIFA works at the Faculty of Medicine and Health Sciences, Universitas Jambi, Indonesia.

|E-ISSN: 2580-5711 |https://online-journal.unja.ac.id/index.php/irje/index | 